\title{
Information Behavior and Political Preferences
}

\author{
KONSTANTIN VÖSSING AND TILL WEBER*
}

\begin{abstract}
This article shows that citizens consider policy positions for the formation of their political preferences when they actively seek and find high-quality information, while they dismiss passively acquired and low-quality information. The study develops an extended theory of information and political preferences that incorporates the process of information acquisition and its connection with information quality. A novel experimental design separates the effects on political preferences due to information behavior as an activity from those due to selective exposure to information. The study applies this design in a laboratory experiment with a diverse group of participants using the example of issue voting and European integration in the context of the 2014 European Parliament elections.
\end{abstract}

Keywords: information; information behavior; information quality; political preferences; voting behavior; experiment

Information is a critical foundation of democratic politics. The content and amount of information provided to citizens determine a wide range of political preferences, including judgments of issue relevance, ${ }^{1}$ evaluations of politicians, ${ }^{2}$ vote choices $^{3}$ and policy opinions. ${ }^{4}$ The manifold mechanisms through which information shapes the formation and expression of these preferences include information updating, ${ }^{5}$ agenda setting, ${ }^{6}$ priming, ${ }^{7}$ framing ${ }^{8}$ and persuasive appeals. ${ }^{9}$

Despite the significance of information for political preferences and a large body of scholarship on the topic, the process through which citizens acquire political information in the first place has attracted little scholarly attention. Does the impact of information on political preferences depend on whether citizens are passive recipients or active seekers of information?

* Humboldt University Berlin, Institute of Social and Political Sciences (email: konstantin.voessing@ hu-berlin.de); Baruch College, City University of New York (email: till.weber@baruch.cuny.edu). We are grateful for having had the opportunity to present our research at the Montréal voting experiments workshop, the MPSA Conference 2014, a workshop at the Center for European Studies at Harvard University and the Comparative Politics Research Workshop at Humboldt University Berlin. Thanks for helpful comments go in particular to our discussants Richard Lau and Christopher Lawrence, as well as three anonymous reviewers, the editors of this journal and Diana Burlacu. Friederike Talbot provided excellent research assistance and feedback. We also benefited from valuable feedback from our pre-testers, Nicoleta Bazgan, Steffen Beigang, Pauline Defant, Dominik Duell, Cosima Ingenschay, Dorina Kalkum, Thomas Maruhn, Jochen Rehmert, Birgit Reinhold, Marc Reinhold, Carina Schmitt and Marcel Skaun. Konstantin Vössing gratefully acknowledges support from the Deutsche Forschungsgemeinschaft (German research foundation), grant number VO 1990/1-1. Data replication sets are available at http://dataverse.harvard.edu/dataverse/BJPolS and online appendices are available at http://dx.doi.org/doi:10.1017/S0007123416000600.

1 Iyengar, Peters, and Kinder 1982; McCombs and Shaw 1972.

2 McGraw 1991; Vavreck 2009.

${ }^{3}$ Hobolt and Wittrock 2011; Valentino et al. 2002.

4 Hurwitz and Pefley 2005; Tilley and Wlezien 2008.

5 Lenz 2009; Tilley and Wlezien 2008.

6 Iyengar, Peters, and Kinder 1982; McCombs and Shaw 1972.

7 Hart and Middleton 2014; Iyengar and Kinder 1987; Iyengar, Peters, and Kinder 1982; Vavreck 2009.

8 Druckman et al. 2010; Hurwitz and Pefley 2005.

9 Broockman and Butler 2015; Lenz 2009; McGraw et al. 1993. 
Existing research on information updating, priming, agenda setting and framing merely suggests that information needs to be disseminated and then received, while the persuasion framework ${ }^{10}$ presumes that information needs to be received and accepted to affect political preferences. Differences in the question of information acceptance notwithstanding, prior scholarship about information and political preferences relies on a basic model of information provision that does not consider the process of information acquisition.

This article develops an extended model of information and political preferences by theorizing the implications of different forms of information behavior - active information seeking versus passive information acquisition - for the effect of information on political preferences. The model is based on the assumption that information needs to be received, accepted and then retained in memory in order to affect political preferences. We argue that individuals are more likely to retain information they have actively acquired, and are more likely to accept new information when it is of high quality. Citizens only incorporate new policy information into their political preferences when they actively seek and find a high-quality product. We thus expect political preferences to depend on an interaction of information behavior and information quality.

The reliance of existing research on a basic model of information provision and the lack of attention to information behavior is to some extent a natural side effect of randomized experimental designs, which are prevalent in studies of political preferences. Random assignment to political information makes it possible to determine the average treatment effects of information exposure, but it does not allow information seeking as an activity to be disentangled from the factors that make it more or less likely for individuals to seek political information in the first place.

Conventional experiments are thus not equipped to determine whether an effect of encountering information on political preferences stems from the process of seeking information or from individual dispositions that cause selective exposure. ${ }^{11}$ This analytical impasse is also reflected in real-world strategies of political communication and advertisement. Parties and candidates are keenly interested in unloading as much information as possible with ever-higher surgical accuracy onto voters, whose preferences are becoming more and more transparent. In contrast, our theory suggests that both political scientists and political actors would be well advised to address not only the 'big data'-driven amount of information, but also the nuts and bolts of the surrounding individual-level processes of seeking and finding information of varying quality. Designing high-quality policy information, giving voters good reasons to look for information and devising interactive ways to engage that information yields significant effects on party preferences and voting.

To corroborate our claims with evidence, we devise an innovative experimental design that isolates the effects of information seeking as an activity from the impact of selective exposure and its determinants. Our experiment combines conventional random exposure to information in an assignment condition with two additional conditions that entail active information seeking actual self-selection of information versus non-selection (complemented by a model of the selection process), and steered selection, which gives all participants in this condition the (false) impression that they are actively selecting information.

We apply our novel experimental design to the case of issue voting, which occurs when information updating and priming increase the extent to which a specific policy issue is considered in making vote choices. Specifically, we study the extent to which the issue of

${ }^{10}$ McGuire 1985; Zaller 1992.

${ }^{11}$ Case 2006; Klapper 1960; Stroud 2008. 
European integration shapes voting behavior, using a lab experiment conducted with a diverse group of German citizens during the campaign for the European Parliament (EP) elections in May 2014. Participants are randomly assigned to one of the three information behavior conditions explained above. Moreover, to assess the critical function of information quality for the connection between information behavior and political preferences, information within each of the three conditions of information behavior is randomly provided in a high- or low-quality version. Otherwise, the content of the information is the same across conditions, explaining two opposing issue positions about the Europeanization of employment policy, either in favor of European Union (EU) authority or a national approach. To create a realistic information environment, these two positions are assigned to the four political parties represented in the German parliament. Assignment of positions to parties is random, and implemented in such a way that there are always two parties on either side of the issue divide. We discuss below how this strategy is supported by the particular issue chosen for our study and how it yields high experimental realism and generalizable conclusions about voter responses to policy information.

The article is organized as follows. First, we develop our theoretical account. We summarize our argument and outline the basic model of information provision before theorizing the two additional components of our extended model - information behavior and information quality. Secondly, we describe our research design, including the experimental procedures, the leverage gained from the issue used in the study, the selection model and the measurement of key variables. Thirdly, we outline our data analysis and findings. Fourthly, we provide a conclusion and discuss political, theoretical and methodological implications of our research.

\section{AN EXTENDED MODEL OF INFORMATION AND POLITICAL PREFERENCES}

Our extended model of information and political preferences relies on the study of issue voting as an example of a process in which a political preference is affected by the provision of information. It elaborates on the two jointly occurring mechanisms of information provision that have previously been shown to cause increased issue voting - information updating and priming. The model can be extrapolated to other political preferences and mechanisms of information provision that affect political preferences, such as agenda setting, framing and persuasion, since all these mechanisms are based on the same basic model of information provision that excludes the process of information acquisition.

Issue voting occurs when voters express support for a political party or a candidate whose supply of issue positions provides the greatest match with their own demand. ${ }^{12}$ Information updating is the most fundamental prerequisite for issue voting, as it gives voters the necessary informational input to match their own views to varying party positions, ${ }^{13}$ while the concurrent process of priming increases the significance of the issue as a standard for political evaluations. ${ }^{14}$ Priming information about a particular issue makes considerations related to the issue more accessible in memory, which raises the salience of the issue and its relative weight in vote choices.

We treat information updating and priming as concurrent mechanisms that jointly translate information into political preferences. For this purpose we use experimental treatments that

\footnotetext{
12 The 'directional' model (Rabinowitz and Macdonald 1989) elaborates on the traditional 'proximity' model (Downs 1957), but both approaches are based on the same idea that voting occurs on the basis of issue affinities. We explain below how this is reflected in our measurement choices.

13 Lenz 2009.

14 Iyengar and Kinder 1987.
} 
always initiate both mechanisms by underlining the importance of an issue as well as providing new information about party positions on the issue. This scenario enhances the realism of our experiment in that it closely resembles real-world campaign information, which will rarely prime an issue without saying anything about party positions or merely announce party positions without saying anything about the issue. Irrespective of this choice, however, the two mechanisms are theoretically distinct and can be studied separately with proper analytical provisions. ${ }^{15}$

\section{Receiving Information}

Existing arguments about the effects of information updating and priming on issue voting rely on the basic model of information provision. They suggest that information merely needs to be received in order to shape political preferences. Parties and other elite actors can thus increase the influence of a particular issue on vote choices simply by making sure that information is effectively disseminated to its targets. For instance, in our empirical case of issue voting and European integration, prior research has shown that vote choices are affected by a combination of information updating and priming when citizens receive information about the issue, ${ }^{16}$ while EU issue voting decreases when information is diluted. ${ }^{17}$ As our research is based on giving voters information about a European integration issue, we would expect to find support for the classic issue voting hypothesis (Hypothesis 1), according to which a match of policy preferences between individuals and parties over the desired scope of European integration should affect vote choice.

HYPOTHESIS 1 (Classic issue voting hypothesis): A greater match of policy preferences between an individual and a party makes it more likely that the individual will vote for the party.

Mediated by successfully updated information and greater issue salience, the provision of information should increase, overall, the extent of issue voting in a diverse group of citizens. We develop an extended model of information and political preferences by arguing that this type of effect is essentially conditional. It depends on the acceptance and retention of newly received information. Receiving high-quality information favors information acceptance, which facilitates better information retention through active information seeking. High-quality information and information seeking thus serve as critical catalysts for information updating, increased issue salience and eventually a greater effect of information on political preferences. ${ }^{18}$

15 See Lenz 2009. An additional explanation for a correlation between issue positions and political preferences resulting from the provision of issue-related information is projection (Hart and Middleton 2014; Lenz 2009). While in the case of priming and updating people adjust their preferences according to their position on the issue concerned, the causal effect is reversed in the case of projection. Following the suggestions of Hart and Middleton (2014) and Lenz (2009), we exclude the possibility of projection by measuring participants' issue positions before the administration of the information treatment.

16 De Vries et al. 2011; Hobolt and Wittrock 2011.

17 Weber 2009.

18 Our model intentionally distinguishes between scope conditions and catalysts here. The effect of information on political preferences is conditioned on information acceptance and retention. High-quality information favors the former, and information seeking improves the latter. However, high-quality information and information seeking are catalysts and not scope conditions, because other factors might have similar effects on information retention and acceptance. 


\section{Retaining Information}

As the first of two catalysts for the effect of information on political preferences, we propose that active information behavior favors the consideration of new information by improving information retention. The juxtaposition of the active seeking and passive acquisition of information constitutes the most crucial distinction between different types of information behavior. ${ }^{19}$ Selective exposure is the result of information behavior, but rather than the activity of obtaining information, it identifies the biases in information exposure and their determinants. For instance, individuals with lower levels of political interest or sophistication are considerably less likely to expose themselves to political information. Selective exposure has received a lot of theoretical and empirical attention in political science, ${ }^{20}$ while information behavior has remained heavily undertheorized.

We argue that variation in information behavior, independent of selective exposure and its determinants, affects political preferences by regulating the extent to which information is retained in memory before it is considered for vote choices as well as for other preferences and judgments. Hypothesis 2 formulates the expectation of a preliminary theory of information behavior and political preferences (not yet incorporating the role of information quality as the second moderating factor, which is explained below). According to this perspective, actively seeking information, as opposed to passive acquisition, should increase the extent to which individuals retain the information in memory, prompting them to consider the issue covered in the information more strongly for their vote choices and other political preferences.

HYPOTHESIS 2 (Preliminary information-seeking hypothesis): If individuals actively seek (and find) information, the process of doing so makes them develop their political preferences more strongly on the basis of the issue covered in the information.

Prior research has demonstrated that active information seeking is superior to passive acquisition for effective information retention in many different learning tasks, such as learning languages $^{21}$ or computer software. ${ }^{22}$ While the motivations and abilities that guide general learning only partly overlap with those that guide the engagement of political information, the cognitive process of encountering policy information, retaining it in memory and using it (or not) for political preferences such as vote choices is equivalent to other tasks involving information retention. Active information behavior should thus improve not only information retention in various learning tasks, but also the extent to which individuals retain political information.

The volitional control afforded by active information behavior offers a wide range of benefits for information retention, including the ability to select the most relevant content from a pool of information. ${ }^{23}$ However, even when that option is unavailable, as in our study, just the ability to make decisions about retrieving information ${ }^{24}$ and the ensuing intervention ${ }^{25}$ increase learning success. Markant et al. show that even the most minimal degree of intervention (pushing a button to continue a test) is sufficient to improve the retention of information. ${ }^{26}$ Decision and

19 Bates 2002; Bruner, Goodnow, and Austin 1956; Case 2007; Harman, Humphrey, and Goodale 1999; Johnson 1997; Markant and Gureckis 2013.

20 Kinder 2003; Klapper 1960; Stroud 2008; Sunstein 2001; Zaller 1992.

21 Atkinson 1972.

22 Bell and Kozlowski 2008.

23 Bruner, Goodnow, and Austin 1956.

${ }^{24}$ Leotti, Iyengar, and Oshsner 2010.

25 Sobel and Kushnir 2006.

26 Markant et al. 2014. 
intervention enhance information retention by facilitating better coordination of information exposure and engagement, ${ }^{27}$ and by sustaining causal exploration as a particularly effective mode of information processing. ${ }^{28}$ According to a preliminary theory of information behavior, once actively seeking information has improved information retention, the ensuing information updating in conjunction with an increase in the accessibility of the information and the salience of the issue should ultimately yield a greater weight of the issue in the formation of political preferences, evidenced in our case by more extensive issue voting.

\section{Accepting Information}

We now elaborate further on the preliminary theory of information behavior by introducing information acceptance as a second scope condition for the effect of information on political preferences and by arguing that high-quality information functions as a catalyst for information acceptance. We thus propose that the entire causal process that unfolds from active information behavior to information retention, and eventually an increased weight of the information in the formation of political preferences, depends on whether citizens first accept the information they encounter. In research on persuasion, accepting information ${ }^{29}$ or 'yielding' to it, ${ }^{30}$ after it has been received, is a prerequisite for attitude change. We argue that information acceptance conditions the effect of information not only on policy attitudes but also on other types of political preferences, for instance party choices in a process of issue voting.

We expect higher-quality information to increase the likelihood of information acceptance and thereby to facilitate the effect of information seeking on information retention and the subsequent increase in the impact of information on political preferences. Our argument builds on the elaboration likelihood model (ELM) of preference formation. ${ }^{31}$ The ELM suggests that individuals need to be motivated to engage in systematic information processing ('central route') instead of relying on heuristic shortcuts ('peripheral route'). The ELM further suggests that motivated individuals who do process information will only accept incoming information when it is of sufficiently high quality.

We argue that the very process of active information seeking, as one of several possible triggers, raises people's motivation to process information. The motivation generated by the process of information seeking then needs to be 'rewarded': seeking information implies the expectation of finding a high-quality result. If this expectation is fulfilled, the information is accepted, and the acceptance and retention of information interactively affect political preferences. Finding low-quality information, by contrast, should lead to frustration and prevent an effect of information on preferences by prompting individuals to dismiss the information. High-quality information should thus support the connection between active information behavior and a greater impact of information on political preferences by facilitating information acceptance for all active information seekers.

The expectation of an interaction between information seeking and information acceptance is also sustained by studies of cognition and learning. This research demonstrates that the positive effect of active information behavior on information retention depends on various moderating factors, including the quality of learning materials. ${ }^{32}$ Active learners need to encounter

${ }^{27}$ Bruner, Goodnow, and Austin 1956; Harman, Humphrey, and Goodale 1999; Markant et al. 2014.

${ }^{28}$ Bruner, Goodnow, and Austin 1956; Markant and Gureckis 2013; Sobel and Kushnir 2006.

29 Zaller 1992

${ }^{30}$ McGuire 1985.

${ }^{31}$ Petty and Cacioppo 1986.

${ }^{32}$ See, for example, Atkinson 1972; Paas, Renkl, and Sweller 2004. 
adequately designed instructional materials to achieve improved information retention, just as active seekers of policy information need to find high-quality information products. The expectation of an interaction between information behavior and information quality in the formation of political preferences is thus supported by two distinct scholarly traditions. It is summarized by our Hypothesis 3, which completes our extended model of information and political preferences.

HYPOTHESIS 3 (Information quality and information-seeking hypothesis): The higher the quality of political information, the more the very process of seeking (and finding) information reinforces the connection between information, issue considerations and political preferences.

\section{EXPERIMENTAL DESIGN}

We test our theoretical expectations using an experimental design (illustrated in Figure 1) that manipulates information behavior and information quality. ${ }^{33}$ The administration of the treatments builds on popular voter advice applications (VAAs) that allow citizens to access information about the policy proposals of political parties and compare them to their own preferences to inform their vote choice. Participants are exposed to a reproduction of the official website of the German VAA for the EP elections of 2014, which is administered by the reputable Federal Agency for Civic and Political Education (bpb). This particular channel is merely a convenient strategy to communicate our cover story, according to which we are interested in the use of new technologies for political communication. Conveniently, the bpb and VAAs in general have an excellent reputation. Recent studies show that VAAs are perceived as useful and trustworthy tools that affect voting behavior in the real world, even after controlling for self-selection bias. ${ }^{34}$

But VAAs are not of substantive interest to our research, and participants do not actually get to use a VAA in the experiment. They first read a brief mock article, devoid of political content, explaining the purpose of VAA technology. The policy information is contained in a second article allegedly designed to illustrate the procedure through which party positions are funneled into the application. This second article states that the people in charge of the VAA explore the policy statements parties disseminate for the upcoming EP elections. The article then explains that party positions are assigned to different thematic fields, so that users can identify the match between their own preferences and the positions of all major German political parties for a wide range of issues.

The text next illustrates the operating procedures of the VAA by discussing the issue of the Europeanization of employment policy, allegedly as an example. The two possible positions here are Europeanization (giving the EU more authority to fight unemployment) or the continued pursuit of a national approach (leaving competences and financial resources at the national political level). Each participant who receives the treatment is confronted with both policy positions. In the treatment article, the two opposing positions are randomly assigned to the four parties represented in the German parliament: the Christian democratic CDU/CSU, the

\footnotetext{
33 We produced an online appendix, available at dataverse.harvard.edu/dataverse/BJPolS, which reports information on experimental protocols and treatments as well as complementary statistical analyses. In keeping with the standards of transparency and accuracy endorsed by the Open Science Framework, we have reported, to the best of our knowledge and abilities, all measures, conditions, sampling and recruitment procedures, data analysis procedures and experimental protocols pertaining to this research.

34 Alvarez et al. 2014; Vassil 2011.
} 


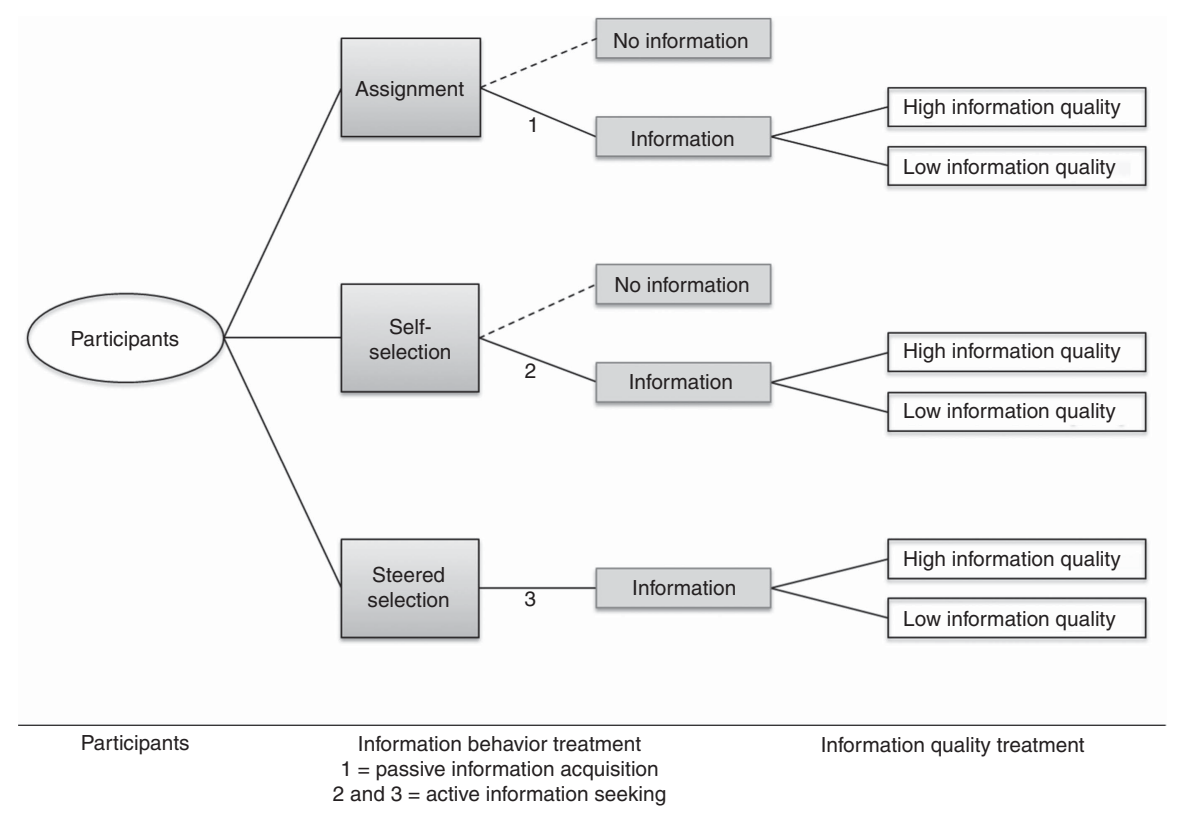

Fig. 1. Experimental design

social democratic SPD, the eco-libertarian Greens and the socialist Left Party. Randomization avoids any distortive association of policy positions with the popularity of these parties in our sample, and - as discussed in the following section - it is plausible for the issue at hand. The procedure is conducted in such a way that there are always two parties - any two parties - on either side of the issue, thereby producing six different constellations of party conflict. To exclude the possibility of confounds through ordering effects, we also randomized the order in which the two parties assigned to the same issue position appear in the article.

To trigger different forms of information behavior, participants are randomly assigned to one of three modes of information provision after having read the apolitical first article. Participants directed into the assignment condition are randomly assigned to either receive the second article containing the policy information or to proceed directly with the questionnaire. This condition thus entails passive information acquisition, which is the typical mode of operation in existing research about the impact of various mechanisms of information provision on political preferences (as outlined in the introduction).

Using different techniques, the self-selection and steered selection conditions both trigger information seeking as a generic form of information behavior rather than prompting individuals to find specific and narrowly defined information. In the self-selection condition, participants are given the option to read the second article containing our policy information or to proceed without reading it. Opting for the information implies active seeking, while the nonseeking participants in this category choose to avoid the information. Echoing an argument of Gaines and Kuklinski, the self-selection condition thus incorporates active treatment selection into the experimental design, similar to the work of Arceneaux and Johnson as well as Druckman, Fein and Leeper, but for a different explanatory purpose and combined with a model of the selection process. ${ }^{35}$ We trigger the generic process of information seeking and enhance

35 Arceneaux and Johnson 2013; Druckman, Fein, and Leeper 2012; Gaines and Kuklinski 2011. 
the realism of our design by phrasing the selection option in terms of a discussion of new debates in the 2014 EP elections, rather than telling participants to specifically look for information about party positions.

In the steered selection condition, active information seeking is induced for all participants who were randomly assigned to this category. Rather than allowing participants to opt out of the information, they are allegedly given a choice between two different articles, introduced to them as discussing either the political debates informing the VAA or the technology behind it. However, irrespective of their choices, all participants receive the same article containing our policy information that is also used in the other conditions. We phrased the article so that its content appears plausible both as a technical and a political text. ${ }^{36}$ In the steered selection condition, information seeking is thus induced by giving participants the impression of actively selecting between different types of information. This strategy avoids the composition effects that are inevitably present in the self-selection condition.

Prior experimental research on cognition and learning uses 'yoked designs' to simulate the distinction between active information seeking and passive information acquisition. ${ }^{37}$ In this type of experiment, participants perform a learning task, either as self-directed learners allowed to make their own learning choices or as 'yoked' learners, who receive the exact same sequence of information as one of their active counterparts without having any control over the process of information acquisition. This design holds the content of the information constant between active seekers and passive information recipients, but it may be less effective at isolating the role of information behavior. It is possible that passive information recipients in 'yoked designs' are at a disadvantage compared to active learners not because of the hypothesized benefits of information seeking, but rather due to being exposed to a sequence of information that comes straight from the mind of a different individual, which has not been created for the purpose of effective instruction or information provision. Our experimental design avoids this pitfall of yoked designs by implementing other ways of inducing active versus passive information acquisition. Moreover, yoked designs are not concerned with the broader problem of self-selection into the information, which we address by combining random assignment with a self-selection component.

To test the effects of the interaction between information behavior and information quality, all participants who receive information in one way or another are randomly assigned to receive it in either a high- or low-quality version. The broader debate about the quality of information and argumentation is eclectic and controversial, with contributions from a wide range of disciplines. However, for information about the policy positions of political actors investigated in our study, prior research suggests more unanimously that the quality of information depends primarily on the sophistication of the justification that is provided for varying policy positions. ${ }^{38}$

Following this literature, high quality in our treatment is expressed through a more plausible and sophisticated justification of different positions. According to Areni and Lutz, more plausible and sophisticated justifications of party positions increase the quality of information by making it appear more likely that the measure for which parties express support (in our case, Europeanization or national control) will indeed advance the envisioned goal (in our case, employment). ${ }^{39}$ Empirical studies about the quality of deliberative democracy, ${ }^{40}$ as well as

${ }^{36}$ See the online appendix for reproductions and English translations of the instructions and the treatment article.

${ }^{37}$ Harman, Humphrey, and Goodale 1999; Markant et al. 2014; Voss et al. 2011.

38 Areni and Lutz 1988; Broockman and Butler 2015; McGraw 1990, 1991; McGraw et al. 1993; Steenbergen et al. 2003 .

${ }^{39}$ Areni and Lutz 1988.

${ }^{40}$ For example, Steenbergen et al. 2003. 
research about elite influence on public opinion, ${ }^{41}$ come to the same conclusion - that more sophisticated justifications of a political view are a key feature of high-quality information. ${ }^{42}$

Data collection for the experiment was conducted during the last two weeks of February and the first two weeks of May 2014. The study was implemented in the experimental laboratory at the Institute of Social and Political Sciences at Humboldt University Berlin with a diverse group of 342 participants who reflect the variation in key socio-demographic features of the German electorate. The sample covers the age range of eighteen to seventy-eight, both genders (55 per cent female), all education levels from grade school dropouts to $\mathrm{PhDs}$, as well as diverse income situations such as students, interns, employees, freelancers, homemakers, pensioners and work seekers. Conducting the experiment with a diverse group of participants in a laboratory environment supports the effective combination of internal and external validity in our study.

Of the 342 participants, 165 were students recruited from a participant pool database, who received course credit or a small honorarium for participating in the study. The remaining 177 participants were recruited through a database of a wide range of different clubs and associations as well as classified ads. ${ }^{43}$ They received a compensation of 15 euros. Completing the experiment took around twenty minutes, informed consent was solicited before the beginning of the study, and the protection of participants, including appropriate debriefing, was guaranteed according to the guidelines prescribed by a typical Institutional Review Board (IRB). ${ }^{44}$ Portrayed as research about the use of digital technologies for political communication, the study was conducted on individual computer stations in the experimental lab. After providing informed consent, participants answered a series of pre-treatment questions, went through the experimental procedure and then responded to manipulation checks, measures of our dependent variable and other post-treatment items. All survey questions that could possibly have been affected by the treatment (in particular participants' policy views and party identifications) were placed in the pre-treatment stage. The large sample size allows us to divide participants into the eight conditions (defined by mode of information acquisition and information quality) while retaining statistical power. The online appendix contains a frequency table, which also shows that the distribution of student and other participants is roughly equal across conditions.

\section{VIRTUES OF THE MANIPULATED ISSUE}

We selected the discussion about the Europeanization of employment policy as the exemplary issue used in this study because it represents a meaningful, important and controversial issue, which at the same time lends itself perfectly to our manipulation, as one rare issue for which all six possible combinations of parties and issue positions are feasible and plausible. This is the

\footnotetext{
${ }^{41}$ Broockman and Butler 2015; McGraw 1990, 1991; McGraw et al. 1993.

${ }^{42}$ Note that the high-quality version of our treatment is also longer than the low-quality version. We discuss below why information quality (rather than length) is the critical factor in our study.

${ }^{43}$ One might suspect inflated treatment effects in the student sample because young people have lessdeveloped political identities. However, the opposite effect occurs in our data, indicating that students may well be less settled, while their cognitive resources make them more critical when accepting or rejecting information in the first place (see Zaller 1992). The inclusion of the student sample is thus a conservative move. Excluding it and relying on the more diverse sample of other participants alone would produce even stronger support for all hypotheses.

${ }^{44}$ We used the procedures published by the IRB at Ohio State University as our frame of refer orrp.osu.edu/irb/.
} 
case, to begin with, because employment as a political goal is unequivocally shared by German parties and voters, so that the controversy portrayed in the treatment article revolves exclusively around the scope of EU authority over employment policy. In other words, the question is not about the importance of creating new jobs but about the best way to do this. European integration, in turn, is a typical 'cross-cutting' issue. While the political left thinks of the EU as a vehicle for cross-border regulation, the political right sees integration as an opportunity to liberalize national markets. ${ }^{45}$ As both sides are aware of the double-edged blade, each party harbors considerable internal conflict and pronounced within-party variation of preferences over the issue. ${ }^{46}$ In addition, overall positions show relatively little variation across parties. ${ }^{47}$

Moreover, parties that are not explicitly founded on mobilizing anti-EU sentiments (and none of the four included parties are) avoid distinct positions and direct confrontation over integration policies. ${ }^{48}$ EP elections are essentially 'second-order' contests fought over national issues rather than questions of integration. ${ }^{49}$ The particular features of the issue and the party behavior it entails are reflected in public opinion: voters have distinct preferences of their own, but they are highly uncertain about party positions toward European integration. In an EU-wide survey study, ${ }^{50} 40$ per cent of voters were unable to place parties on an issue scale about a European employment program, and among those who did respond, agreement of the perceived positions was less than half of what it is for left-right positions. A similar pattern was found for general positions toward integration. ${ }^{51}$ Even in countries where the EU is heavily contested at the elite level, such as the UK, perceptions of competing party positions can be manipulated experimentally. ${ }^{52}$ Overall, European employment policy lends itself to our manipulation because it is a salient issue, which is at the same time not described by entrenched party positions. $^{53}$

Using the debate about the Europeanization of employment policy in our study also allows us to draw generalizable conclusions about voter reactions to policy information that extend to political issues at large. This is the case because the unique features of the issue facilitate a high degree of experimental realism, that is, congruence between the real-world political processes we are investigating and the processes occurring within the experiment. In the context of our research, experimental realism requires a real issue (the debate about the Europeanization of employment policy) that speaks to real voter preferences (about the scope of European integration), rather than a hypothetical scenario or an uncontroversial topic that participants would easily dismiss. Moreover, experimental realism is also favored by the particular qualities

45 Hooghe and Marks 1999.

${ }^{46}$ Hix and Lord 1997.

47 The 2002 Chapel Hill Expert Survey of national parties and the EU contains an item concerning European employment policy. On the seven-point scale, the standard deviation of the parties included in our experiment is a mere 0.64. The standard deviation of the closest equivalent in the 2014 Survey (EU authority over economic and budgetary policies) is somewhat higher but still limited (1.16).

${ }^{48}$ Van der Eijk and Franklin 2004.

${ }^{49}$ Reif and Schmitt 1980.

${ }^{50}$ Van der Brug and Van der Eijk 1999.

51 Weber 2007.

52 Tilley and Wlezien 2008.

${ }^{53}$ Empirical analysis supports our claim that there is no systematic relationship between political parties and preferences over the proper polity level for fighting unemployment. Correlations between individual party identification and opinions about the Europeanization of employment policy are clearly non-significant $(p>0.1)$ for all included parties ( $\mathrm{r}=-0.11$ for CDU, 0.004 for SPD, 0.11 for Left Party, and 0.13 for Greens). Of course, the participants of our study may still have rudimentary pre-existing beliefs regarding party positions on European employment policy. To the degree that this is the case, it will be harder to find an effect of our randomized treatment. 
of the issue at the elite level (vague party positions, low variation between them and pronounced within-party conflict), because they allow us to randomly assign clear positions to parties in the experiment, which would be impossible for an issue with party positions that are already clear in the real world. This makes it possible to simulate a real-world situation in which parties take clear positions (which reflects the typical political issue to which we want to extrapolate our findings), while at the same time excluding all party-specific effects through the random assignment of parties to different positions.

\section{SELECTION MODEL}

Introducing active treatment selection into our experiment makes mechanisms of information behavior accessible to experimental scrutiny that are usually reserved for observational research. However, the option of self-selecting information triggers not only different types of information behavior. It also introduces selective exposure to information as a potential confounder reflected by the difference in composition between individuals who are disposed to actively seek information and others who are disposed to avoid it. It is thus possible that a positive finding regarding information seeking would only reflect characteristics of self-selected seekers that have nothing to do with the mechanism underlying our hypothesis. To identify this composition effect and separate it from the proper effect of information seeking itself, we estimate a statistical model of the self-selection decision and construct a propensity-score weight (PSW) on the basis of the model's predictions. This is a standardized statistical procedure developed by Rosenbaum and Rubin as well as Imbens ${ }^{54}$ with straightforward implementation:

a) In a first step, probit regression is used to estimate the binary choice between avoiding (0) and seeking (1) information for the 139 participants in the self-selection condition. Table 1 shows the estimation results (predictor variables are discussed below).

b) For each individual, the model predicts the probability $P$ that a participant with this particular set of covariate values would choose to seek information.

c) The PSW is then calculated as $1 / P$ for participants who sought information, and as $1 /(1-P)$ for those who avoided it. (The other conditions - assigned information and steered selection receive the default value of 1 .)

d) To correct for the difference in composition in the self-selection condition, the PSW will be applied to weight cases in three models (4, 7 and 8 in Table 2) of the treatment effect of policy information on party preferences.

Models of information seeking in the real world can be very comprehensive. ${ }^{55}$ In our study we expect that composition effects will be relatively minor, and their determinants less numerous compared to observational data. This is because our experiment controls almost all circumstances of the self-selection situation and its immediate history - except, of course, the ultimate decision to seek or avoid the information. Predictors of this choice were chosen for two complementary reasons. The first group includes typical determinants of information exposure: experimental session, party ID, opinion leadership, need for cognition, political

\footnotetext{
54 Imbens 2000; Rosenbaum and Rubin 1983. The PSW approach is particularly helpful for our aim of modeling a phenomenon that essentially represents the relationship of two variables (policy match and vote propensities). If the phenomenon of interest were simply the level of one variable, we could use control variables directly in the outcome equation.

55 For example, Case 2007; Johnson 1997.
} 
TABLE 1 Probit Estimates for the Selection Model

\begin{tabular}{lcc}
\hline \hline & Marginal effects & Standard errors \\
\hline Session mean (de-selfed) & 0.15 & $(0.20)$ \\
Party ID (baseline: none) & & \\
CDU/CSU & $-0.25+$ & $(0.14)$ \\
SPD & $-0.28^{* *}$ & $(0.11)$ \\
LINKE & $-0.37^{*}$ & $(0.15)$ \\
GRÜNE & $-0.19+$ & $(0.11)$ \\
Other & -0.18 & $(0.13)$ \\
Opinion leadership & -0.06 & $(0.26)$ \\
Need for cognition & $0.35^{*}$ & $(0.16)$ \\
Political sophistication & -0.11 & $(0.17)$ \\
EU interest & -0.48 & $(0.31)$ \\
EU support & $0.97^{* *}$ & $(0.32)$ \\
EU salience & $-0.47^{*}$ & $(0.22)$ \\
Job market salience & 0.04 & $(0.15)$ \\
Left-right position & -0.02 & $(0.02)$ \\
Left-right position: extremism & 0.03 & $(0.03)$ \\
Class (baseline: working class) & & \\
Lower middle class & 0.11 & $(0.15)$ \\
Middle class & $0.17^{*}$ & $(0.08)$ \\
Upper middle class & $0.18+$ & $(0.11)$ \\
High school graduate & $-0.16^{*}$ & \\
Qualification (baseline: none) & & \\
Vocational & 0.16 & $(0.11)$ \\
Academic & 0.16 & $(0.11)$ \\
Occupation (baseline: retired) & & $(0.18)$ \\
Unemployed & -0.05 & $(0.12)$ \\
Student & $0.26^{*}$ & $(0.16)$ \\
Self-employed & 0.15 & $(0.14)$ \\
Employed: academic & 0.22 & \\
Employed: vocational & 0.02 & \\
N Nagelkerke's R-squared & 139 & \\
Per cent correctly classified & 0.332 & \\
\hline \hline & 80 & \\
\hline
\end{tabular}

Note: marginal effects on $\operatorname{Pr}(\mathrm{Y}=1)$; estimated at means for continuous variables and as first differences for categorical variables. Robust standard errors in parentheses, clustered by session. $+\mathrm{p}<0.10,{ }^{*} \mathrm{p}<0.05, * * \mathrm{p}<0.01$

sophistication and - as the choice was framed in the context of EP elections - interest in European politics, attitudes toward European integration and subjective salience of integration policy. Predictors in the second group were chosen on the basis of likely correlations with the treatment effect. As the information presents party positions on labor market policy, we included subjective salience of labor market policy, left-right position, social class, education and training, and occupation. See the online appendix for measurement details.

As shown in Table 1, the performance of the model constructed from these variables is highly satisfactory; 80 per cent of the cases are correctly classified as seeking or avoiding information, respectively. Notwithstanding this result, however, it is important to point out that no statistical estimate is perfect. The introduction of active selection into our experiment leaves some uncertainty as to potential composition effects not captured by our model. This is the reason why we also included 'steered selection' as an alternative way of testing the effect of 
information seeking. As explained above, all participants in this condition receive the same policy information while they believe they are actively selecting it. The advantage of steered selection is that no composition effects can occur. The advantage of self-selection is its realistic opt-out possibility. By triangulating these two strategies, we aim to maximize the robustness of our analysis.

\section{MEASUREMENT}

Our main dependent variable is a measure of party preference called 'propensities to vote' (PTVs), which asks participants to indicate the propensity on eleven-point scales that they 'will ever vote for' each of the four included parties. The PTV battery is a long-standing survey instrument that has been included in numerous national and international election studies. The question is explicitly designed to measure the generalized electoral utility a voter derives from supporting a party; it is closely linked to vote choice, and it accommodates differentiated preferences. ${ }^{56}$ It thus lends itself to our purpose of testing reactions to an experimental manipulation of issue positions in multiparty systems.

PTVs are recorded for each of the four parties, so that the resulting dataset has a multilevel ('stacked') structure, including party per participant at the lowest level, followed by the participant and eventually the party constellation. To control for the fact that the observations within participant and party constellation are not independent, we use random intercept models at the level of participants and robust standard errors clustered by party constellation. ${ }^{57} \mathrm{We}$ also control for individual levels of identification with the four included parties using a set of 'thermometer' questions. They ask participants to indicate on 0-100 scales how 'cold' or 'warm' they feel toward each party, with higher values representing greater levels of identification.

To model the effect of the policy treatment on the PTVs, the stacked structure of our data is key. As explained, each participant is represented by four rows in the dataset, one for each party, and the treatment positions were randomly assigned to parties. The expected correlation of the assigned party positions with the PTVs is thus zero, because whether a certain position has a positive or negative effect on a certain respondent's party preference depends on that respondent's own policy position. We thus model the extent of issue voting with a 'policy match' variable. The stacked data structure allows us to create this variable according to the match between the participant's attitude toward the scope of European integration and each of the randomly assigned party positions. Importantly, participant attitudes were measured before the treatment, so that competing explanations that bedevil observational studies of issue voting (in particular persuasion, cue taking from parties and rationalization) can be excluded.

Specifically, participants answered a battery of questions asking for each of twelve policy fields whether decisions in that field should be 'rather made by one's home country' or 'rather made by the EU'. ${ }^{58}$ A preference for EU competence in all twelve fields is coded

${ }^{56}$ Van der Eijk et al. 2006.

${ }^{57}$ Fixed effects were not deemed necessary as they produced virtually identical results.

58 The policy fields are immigration, unemployment, environment, fiscal policy, defense, media, health, science, education, labor law, foreign policy and internal security. We found a composite score to be more reliable than a single employment item that would be a more direct equivalent of the party positions in the treatment article. This reflects deliberate design choices: respondent position was asked before the treatment raised awareness of the employment issue, thus avoiding reverse causality, and it was included in a low-stimulus issue battery to avoid attracting undue attention before the manipulation. Besides these technical matters, the 
as 0.5 , a preference for national competence in all fields as -0.5 . All other combinations are located on a linear scale connecting the two extremes, with a neutral zero point in the middle. These scores are then multiplied by the assigned party positions, coded 1 for the European approach to employment policy and -1 for the national approach. If the participant and party agree on the policy direction, the resulting variable thus takes on a positive value and increases with the participant's attitude score. If the participant and party favor opposite directions, the resulting variable takes on a negative value and decreases with the subject's score. ${ }^{59}$ The policy match variable ranges from -0.5 to $0.5 .^{60}$

\section{ANALYSIS}

As an abiding background condition for any investigation of voting behavior, we expect vote propensities to be affected by separate measures of party identification. Testing this expectation serves to establish the general ecological validity of our data, which reflects the reactions of real voters to real party positions. Moreover, party identification as an observational variable will be important as a baseline for all following experimental tests. Since we apply a post-test only design, controlling for an established determinant of party preferences (which is measured pretreatment) allows us to minimize the natural variance of the dependent variable as well as any residual imbalance of the treatment that is not eliminated by random assignment. This strategy thus allows us to approximate a pre-post-test design while avoiding the undesired effects of asking the same question twice. Model 1 in Table 2 shows how 0-100 thermometer scores of party identifications are related to the 1-11 scale of the PTVs, our dependent variable. A onepoint increase on the thermometer raises the PTV by 0.12 points, a directly proportional translation. ${ }^{61}$

Model 2 tests the classic issue voting hypothesis (Hypothesis 1) using the Policy Match variable, which measures, as explained above, the extent to which a participant's preference regarding the scope of European integration matches the corresponding policy position randomly assigned to each party, on a scale from -0.5 (perfect mismatch) to 0.5 (perfect match). As shown in Model 2, policy match produces a maximum difference on the PTV scale slightly above half a point. This is no overly dramatic effect, but it is of the same order of magnitude as reported in observational studies of integration issues and party preferences. ${ }^{62}$ The classic dictum of 'second-order elections' theory that European integration does not affect preferences

\footnotetext{
(F'note continued)

treatment also seems to activate more general pro/anti integration considerations. In fact, the justifications used for the two positions could equally be used for a range of other issues; they are not specific to unemployment. Accordingly, we found that using a general integration scale to derive respondent positions (the 'Eurodynamometer', a seven-point scale measuring the desired speed of European integration, originally from the Eurobarometer surveys) yields very similar results to those of our issue summary. However, a 'feeling thermometer' scale for the EU does not show any effects. Responses to our treatment are thus somewhat generalized in terms of policy, but not as highly generalized as affective polity evaluations.

59 Our operationalization of policy match is thus compatible with both the traditional 'proximity' model of issue voting (Downs 1957) and the 'directional' model (Rabinowitz and Macdonald 1989), which was shown to be particularly appropriate for the issue of European integration (Dinas and Pardos-Prado 2012).

${ }^{60}$ Participants who did not acquire the information are coded as 0 on the Policy Match variable. This is the exact middle between a positive and a negative match, and represents the expectation of a neutral (zero-size) effect. Exclusion of these cases yields virtually identical results.

${ }^{61}$ Given that party ID is the only observational covariate in Table 2, its coefficient does not change in the visible digits across models.

62 Van der Brug, Franklin, and Tóka 2008; Weber 2009.
} 
for national parties ${ }^{63}$ still receives a lot of support. At the same time, voters appear to be able to formulate opinions on integration issues and relate them systematically to revealed party positions in response to issue-related information. The significant effect of Policy Match in Model 2 also shows that our experimental treatment has the expected impact in the full sample of participants irrespective of information quality and information behavior, and even when individual levels of partisanship are controlled.

Models 3 to 8 (shown in Table 2) test the expectations generated by our extended theoretical model of information and political preferences. Models 3 and 4 test a preliminary information behavior hypothesis (Hypothesis 2), while Models 5-8 evaluate our key hypothesis (Hypothesis 3) about the interaction between information behavior and information quality. Models 4, 7 and 8 are estimated using the PSW, so that the covariates that predict information seeking shown in Table 1 are balanced across different modes of information acquisition. If our selection model is adequate, any remaining differences between the groups in the weighted regressions of these models can therefore be interpreted independently of composition effects resulting from selective exposure.

To begin with, Models 3 and 4 demonstrate that a preliminary information behavior hypothesis positing the general superiority of active information seeking over passive information acquisition cannot be sustained. Both models, equivalent to Model 2, investigate issue voting, which occurs to the extent that there is a positive association between policy match and vote propensities. However, in contrast to Model 2, which estimates the effect of Policy Match for the entire sample, Models 3 and 4 estimate separate coefficients for Policy Match according to our three modes of information provision (using a continuous-by-categorical interaction). This allows us to make inferences about the extent to which issue voting depends on information behavior, as the random assignment condition involves passive information acquisition, while the two remaining categories of selfselection and steered selection represent different approaches to capturing active information seeking.

The preliminary information behavior hypothesis (Hypothesis 2) suggests that the very process of seeking information (independently of the characteristics that determine selective exposure and make participants more likely to seek information) should increase information retention and issue voting. Model 3 finds the expected, yet statistically non-significant, increase in the effects of Policy Match on voting for active information seeking in both the self-selection and steered selection categories. Including the PSW in Model 4 further raises the value of the Policy Match coefficient in the self-selection group from 0.62 to 0.86 , but the effect remains non-significant. Both models thus provide evidence that points in the direction predicted by a preliminary information behavior hypothesis (Hypothesis 2), yet below conventional levels of statistical significance. As a result, there is no sufficient basis to conclude that active information seeking leads to increased information retention and greater issue voting independent of the quality of the policy information voters are exposed to. Research on learning has shown that the superiority of information seeking for information retention depends on various contingencies in the domain of general learning (see above), and we show here that the same is true for the retention of policy information and the subsequent use of that information in vote choices.

Models 5 to 8 demonstrate that the superiority of information seeking in fostering increased information retention and issue voting depends on the quality of the information voters find. Our Hypothesis 3 formulated the expectation that higher information quality increases the extent to which voters use the acquired information for their vote choices. By estimating the coefficients of Policy Match separately for the three modes of information provision, Models 5

${ }^{63}$ Reif and Schmitt 1980. 
TABLE 2 Linear Estimates for the Treatment Models

\begin{tabular}{|c|c|c|c|c|c|c|c|c|}
\hline $\begin{array}{l}\text { Model } \\
\text { Dependent variable: propensities } \\
\text { to vote (PTV) }\end{array}$ & $\begin{array}{l}(1) \\
\text { Non-experimental } \\
\text { baseline }\end{array}$ & $\begin{array}{l}\text { (2) } \\
\text { Global experimental } \\
\text { effect }\end{array}$ & $\begin{array}{l}\text { (3) } \\
\text { By acquisition } \\
\text { mode }\end{array}$ & $\begin{array}{c}\text { (4) } \\
\text { With propensity } \\
\text { score weight (PSW) }\end{array}$ & $\begin{array}{l}\text { (5) } \\
\text { Low information } \\
\text { quality }\end{array}$ & $\begin{array}{l}\text { (6) } \\
\text { High information } \\
\text { quality }\end{array}$ & $\begin{array}{l}(7) \\
\text { Low information } \\
\text { quality + PSW }\end{array}$ & $\begin{array}{l}\text { (8) } \\
\text { High information } \\
\text { quality + PSW }\end{array}$ \\
\hline Party ID (baseline) & $\begin{array}{l}0.12 * * \\
(0.00)\end{array}$ & $\begin{array}{l}0.12 * * \\
(0.00)\end{array}$ & $\begin{array}{l}0.12^{* *} \\
(0.00)\end{array}$ & $\begin{array}{l}0.12^{* *} * \\
(0.00)\end{array}$ & $\begin{array}{l}0.12 * * \\
(0.00)\end{array}$ & $\begin{array}{l}0.12 * * \\
(0.00)\end{array}$ & $\begin{array}{l}0.12^{* * *} \\
(0.00)\end{array}$ & $\begin{array}{l}0.12 * * \\
(0.00)\end{array}$ \\
\hline Policy match with party (treatment variable) & & $\begin{array}{c}0.54+ \\
(0.31)\end{array}$ & & & & & & \\
\hline Policy match for random assignment ${ }^{i}$ & & & $\begin{array}{c}0.17 \\
(0.48)\end{array}$ & $\begin{array}{c}0.17 \\
(0.48)\end{array}$ & $\begin{array}{c}0.59 \\
(0.47)\end{array}$ & $\begin{array}{c}-0.40 \\
(0.72)\end{array}$ & $\begin{array}{c}0.59 \\
(0.47)\end{array}$ & $\begin{array}{c}-0.41 \\
(0.72)\end{array}$ \\
\hline Policy match for self-selection ${ }^{\mathrm{i}}$ & & & $\begin{array}{c}0.62 \\
(0.45)\end{array}$ & $\begin{array}{c}0.86 \\
(0.56)\end{array}$ & $\begin{array}{c}0.52 \\
(0.44)\end{array}$ & $\begin{array}{c}0.91 \\
(0.59)\end{array}$ & $\begin{array}{c}0.62 \\
(0.58)\end{array}$ & $\begin{array}{l}1.42 * \\
(070)\end{array}$ \\
\hline Policy match for steered selection ${ }^{\mathrm{i}}$ & & & $\begin{array}{c}(0.89 \\
(0.58)\end{array}$ & $\begin{array}{c}(0.89) \\
(0.58)\end{array}$ & $\begin{array}{c}(0.44) \\
0.58 \\
(0.71)\end{array}$ & $\begin{array}{l}1.60 * * \\
(0.47)\end{array}$ & $\begin{array}{c}(0.50) \\
0.59 \\
(0.71)\end{array}$ & $\begin{array}{l}1.59 * * \\
(0.48)\end{array}$ \\
\hline Constant & $\begin{array}{c}0.11 \\
(0.10)\end{array}$ & $\begin{array}{c}0.11 \\
(0.10)\end{array}$ & $\begin{array}{c}0.11 \\
(0.10)\end{array}$ & $\begin{array}{c}0.16 \\
(0.10)\end{array}$ & $\begin{array}{c}0.11 \\
(0.12)\end{array}$ & $\begin{array}{c}0.18^{*} \\
(0.09)\end{array}$ & $\begin{array}{c}0.14 \\
(0.13)\end{array}$ & $\begin{array}{c}0.29^{* *} \\
(0.05)\end{array}$ \\
\hline Observations & 1,368 & 1,368 & 1,368 & 1,368 & 964 & 812 & 964 & 812 \\
\hline Std dev random intercept (respondent level, $\mathrm{N}=342$ ) & 0.95 & 0.95 & 0.95 & 0.90 & 0.99 & 0.94 & 0.92 & 0.85 \\
\hline Std dev residual & 1.53 & 1.52 & 1.52 & 1.50 & 1.48 & 1.58 & 1.47 & 1.53 \\
\hline AIC & 5,368 & 5,364 & 5,365 & 7,745 & 3,748 & 3,241 & 5,799 & 5,296 \\
\hline BIC & 5,389 & 5,390 & 5,396 & 7,777 & 3,777 & 3,269 & 5,828 & 5,324 \\
\hline
\end{tabular}

Note: HLM coefficients with robust standard errors in parentheses, clustered by party constellation. $+\mathrm{p}<0.10, * \mathrm{p}<0.05, * * \mathrm{p}<0.01$

${ }^{\mathrm{i}}$ Interaction terms of the mode of information acquisition (a multinomial variable) with policy match (a continuous variable). For simplicity, the constitutive terms of acquisition mode were omitted. They are clearly insignificant and do not affect any visible digits of other estimates. 
to 8 also make it possible to assess the extent of issue voting for different types of information behavior. However, in contrast to Models 3 and 4, which tested the preliminary information behavior hypothesis (Hypothesis 2), Models 5 to 8 depict the interaction between information seeking and information quality by estimating the contingent effects of Policy Match separately for high (Models 6 and 8) and low (Models 5 and 7) quality. ${ }^{64}$

When the quality of the acquired information is low, the policy match between parties and individuals has no discernible impact on vote propensities, irrespective of whether voters actively seek the information or acquire it passively. This is demonstrated by Model 5, in which the coefficients for Policy Match are statistically non-significant in both categories identifying active information behavior, self-selection and steered selection. The conclusion remains the same when the model is estimated while applying the PSW in Model 7. The coefficient for Policy Match in the self-selection category increases slightly from 0.52 to 0.62 . But still, when information quality is low, even controlling for selective exposure and individual propensities to opt into information through the PSW does not produce significant coefficients for the Policy Match variable in the active information seeking conditions. Figure 2 visualizes the effects and their confidence intervals, showing that information acquisition mode does not play a role for participants who read low-quality information (the dark gray bars).

By contrast, when the quality of policy information is high, voters actively seeking information, who are assembled in the self-selection and steered selection categories, are strongly affected by the stimulus, while voters who passively acquire the information, in the random assignment condition, still appear to dismiss it. To come to this conclusion, Model 6 tests the effects of Policy Match contingent on information behavior for those participants exposed to high-quality information, and Model 8 adds the PSW to exclude the effects of selective exposure in the self-selection category. As predicted by Hypothesis 3, the policy match between party and voter has a significant effect on vote propensities for active seekers (in Model 8; Model 6 addressed below), yet no effect for passive information recipients. ${ }^{65}$

These differences are visualized by the light gray bars in Figure 2. As indicated by the positive coefficients of Policy Match for both the self-selection and steered selection categories, active seeking is conducive to information retention and issue voting, while passive information acquisition is not. ${ }^{66}$

The role of selective exposure in our argument becomes clear when comparing Models 6 and 8 . When selective exposure and individual inclinations to opt into information are not taken into account through the PSW, the Policy Match coefficient for the self-selection category becomes non-significant in Model 6 (even if the coefficient is still positive and larger than for

\footnotetext{
64 An alternative strategy is to add multiplicative interaction terms with information quality to Models 3 and 4 . While this is mathematically identical to splitting the sample by information quality, we believe that the presentation of separate models is clearer. A table with the full interactive specification is in the online appendix. The statistical significance of differences between the models will be evaluated in Figure 2 below. The untreated groups (i.e., respondents who did not receive policy information and were therefore coded 0 on Policy Match: see note 15 above) are used for both low and high information quality (i.e., in Models 5-8).

65 Note that the high-quality treatment was only used in the second run of the experiment, which is closer to the EP elections than the first run. The low-quality treatment still fails to produce effects in the second run, indicating that the decisive variable is indeed information quality, not campaign context.

66 The effects of high-quality information in Figure 2 are significantly larger than 0 , but not significantly larger than the effects of low-quality information, as required by Hypothesis 3 . However, this is essentially an artifact of the aggressive strategy of splitting the sample into eight conditions. When self-selection and steered selection are pooled, the difference between high and low information quality is highly significant $(\mathrm{p}<0.01)$. We deem this sufficient because self-selection and steered selection are different technical implementations of the same concept, namely information seeking. Their empirical effects are also almost identical.
} 


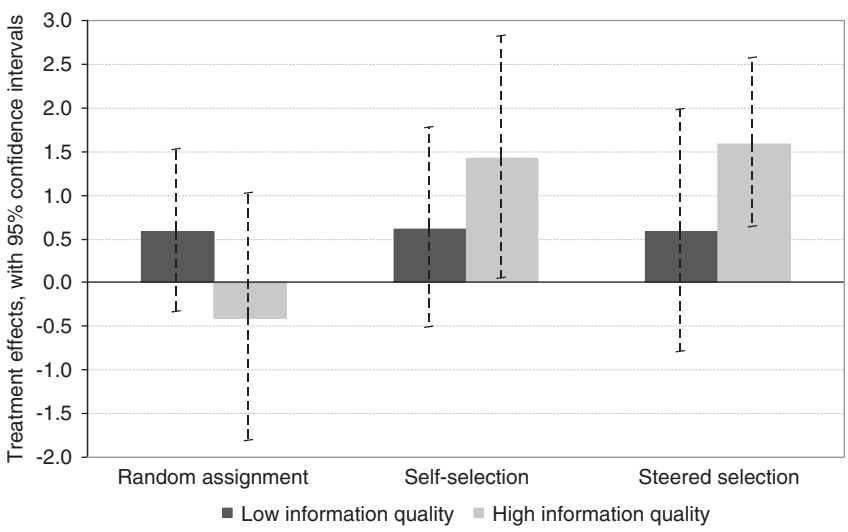

Fig. 2. Effects of policy match on voting propensities by information quality and acquisition mode

low information quality in the corresponding Model 5). This is because individuals who actively seek information are also better prepared to resist new policy information on the basis of their predispositions. ${ }^{67}$ When controlling for this composition effect, as in Model 8, it becomes apparent that even latently skeptical voters are affected by the very process of information seeking. The evidence generated by the contrast between Models 6 and 8 on the one hand, and Models 5 and 7 on the other strongly supports Hypothesis 3. Active information seeking significantly increases the extent to which individuals rely on policy information to cast their vote, as long as the information they encounter is of sufficient quality.

\section{Modeling the Process}

Having found support for the hypotheses generated by our extended theory of information and political preferences, we ran several tests to model the underlying process.

First, we conducted a manipulation check to assess whether variation in information quality was indeed perceived as expected by asking participants how informative they found the text into which the treatment was embedded. The results show that the high-quality version was perceived as more informative. ${ }^{68}$

Secondly, there is evidence that actively seeking participants who find high-quality information indeed assign a higher level of salience to the European integration issue. ${ }^{69}$ This finding is consistent with the priming expectation that information provision about an issue will raise the salience of the issue as a standard of preference formation by making considerations related to the issue more accessible in memory.

67 Zaller 1992.

68 On a five-point scale with a standard deviation of 0.85 , scores were 0.23 higher for the high-quality version ( $\mathrm{p}<0.05$; demographics from Table 1 balanced). This may not seem overly strong, but it is remarkable given that the manipulation concerned only a minor part of the overall text to be evaluated in this particular question. Our proper dependent variable, by contrast, refers to the policy positions only and may thus show stronger effects than the manipulation check.

69 The increase in salience was tested by modeling the probability of participating in EP elections, which was measured post-treatment on an eleven-point scale. For information-seeking individuals with high-quality information, the probability was significantly increased by 0.8 points. Importantly, the regression controlled for the probabilities of participating in three other types of elections (federal, regional, local); therefore this finding can be interpreted as an increase of salience of the European issue in particular. 
Thirdly, another process test shows that actively seeking individuals who find high-quality information indeed engage in greater processing effort when making judgments about their electoral preferences. ${ }^{70}$ This finding is indicative of the information updating mechanism. Successful information updating (which is facilitated by active information seeking and its effect on information retention) triggers more extensive processing for informed issue voting choices than for uninformed non-issue-based votes. Greater processing effort is also consistent with priming: in the process of voting, the consideration of an issue that individuals perceive as more relevant and salient (due to successful priming mediated by the effect of active information seeking on information retention) should take more processing effort than a scenario without successful priming.

Finally, note that the high-quality version of our treatment is also longer than the low-quality version. Participants who fail to enter the central route of information processing might rely on information length as a heuristic for information quality. However, our results clearly suggest that the effects of the high-quality treatment on the more extensive use of information are induced by information quality rather than length. This is because participants in the random assignment condition who are assigned to the high-quality treatment do not exhibit an increased use of information. If information length did constitute a heuristic for information quality, greater issue voting should occur for this group of participants (who are not motivated to enter the central route of information processing as a result of active information seeking). Yet the effect does not occur for them: greater issue voting is reserved for individuals motivated by information seeking to enter the central route, which shows that the effect on issue voting can only be due to variation in information quality. Moreover, the effect in the active seeking conditions compared to its absence in the random assignment condition also demonstrates the value of a persuasion framework, which emphasizes the acceptance of information in addition to its reception. Accepting information or rejecting it, as opposed to just receiving it more or less easily, is critical for the connection between information behavior and the use of information. If low-quality information was merely more difficult to receive, the random assignment condition should show the same effect as the active seeking conditions.

\section{CONCLUSION AND DISCUSSION}

Citizens will consider policy issues to form their political preferences when they actively seek and find high-quality information about these issues. Our research shows that greater attention to political issues depends critically on active information behavior and the provision of highquality information. We investigate the connection between information behavior, information quality and political preferences by studying in a laboratory experiment the extent to which German voters relied on information about the European integration issue to cast their votes in the 2014 EP elections. The increased issue voting we observed stems from information seeking itself rather than the factors that determine whether voters will seek information in the first place. Our confidence in this matter is based on a novel experimental design that isolates information behavior as an activity from the individual proclivities for selective information exposure. To determine the effect of active information seeking on issue voting, the experiment combines random assignment to information with the option of self-selection and a model of the

\footnotetext{
70 Processing duration of the PTV battery used for the dependent variable was significantly increased by about 1 second per party for information-seeking individuals with high-quality information (demographics from Table 1 balanced).
} 
selection process, as well as a third condition of steered selection that makes individuals believe they are actively choosing between different kinds of information even though they are not.

In addition to assuring internal validity through the use of an innovative experimental design and its implementation in a laboratory setting, our research also exhibits a high degree of external validity that considerably surpasses the typical lab experiment. Our claim to external validity is based on using a diverse sample of participants, a realistic information environment, real political parties, the context of a real election campaign and a real issue. ${ }^{71}$ The unique features of the issue (that is, the vagueness, low overall variance and high within-party variation of party positions about the Europeanization of employment policy) allow us to effectively simulate the real-world political process of voter reactions to policy information in the experiment. Real-world party positions on controversial issues are typically clear, which is why such issues cannot be subjected to random assignment of party positions. At the same time, the employment policy issue is salient at the voter level and thus yields meaningful responses. The combination of internal validity and experimental realism guarantees that our conclusions based on this unique issue can be extrapolated to political issues overall.

Our perspective on voters and their ability to meaningfully process issue information is an optimistic one, because we show that citizens can be motivated to incorporate new information about actual political issues into their voting calculus. Whether they do this or not, however, depends on a political environment that fosters meaningful vote choices and the expression of reasoned political preferences rooted in issue considerations by providing high-quality information and interactive ways to engage that information. Our findings suggest that the dismissing of policy information is the result of communication strategies of parties and candidates that may well be highly professional and optimally framed in relation to a particular socio-demographic target, yet frequently of deplorable quality and based on a perception of voters as passive consumers rather than active seekers and participants. Contrary to this perspective, our finding of a positive effect of actively sought high-quality information on the extent of issue voting shows that voters react sympathetically when they are encouraged to seek information and when information providers take them (and their ability to process information) seriously.

Political competition in the real world is often far from this scenario. The country in which we conducted our study, Germany, is a prime example of limited competitiveness through the emergence of catch-all party politics on the left and the 'social democratization' of the right. The relative harmonization of parties' policy positions extends to the entire range of issues, but may best be exemplified by the near absence of conflict over European integration, a fact that we exploited for our experimental manipulation. In the United States, by contrast, increasing competitiveness through rising rhetorical radicalism and polarization along partisan lines coincides with the simultaneous decline in real political competition stemming from recurrent gerrymandering and the unparalleled rise in the number of 'safe' and de facto uncontested electoral districts.

Both overly and insufficiently competitive politics arguably reduce voters' motivation to seek information as a rational basis for their vote choices, by decreasing the significance of votes and issue considerations in less competitive environments, and by drawing voters to rely on partisan

\footnotetext{
${ }^{71}$ In this context, our null finding for passive information acquisition should not be overinterpreted. We deliberately chose a conservative design to improve external validity, but scenarios with a larger general effect of information on issue voting are certainly conceivable. Similarly, using much larger samples would help with small effects such as those of low-quality information. By contrast, using a less trustworthy frame than that of a national VAA would arguably contain the effect.
} 
labels when the political context is excessively competitive. Our study finds that information seeking improves the impact of issue information on voting, but for active information behavior to take place, it requires not only high-quality information and interactive approaches to political discourse, but also a political environment that motivates voters to seek information in the first place. A moderately competitive political environment not only encourages voters to seek political information, it also makes it more likely that they will acquire information from more varied sources and be less constrained by partisan bias. By contrast, excessive competition decreases the occurrence of defection from more rigid partisan affiliations based on issues, while a lack of competition offers few incentives for voters to look beyond easily acquired partisan labels. Our study tries to disentangle selective exposure from information behavior to isolate the impact of information seeking on issue voting. Importantly, by raising the degree to which information is considered for vote choices, active seeking reinforces any positive effect of political contextual changes affecting selective exposure. Actively seeking and finding information of high quality thus enhances not only the quality of political discourse. It may also function as an antidote to partisan polarization.

\section{REFERENCES}

Alvarez, Michael, Ines Levin, Peter Mair, and Alexander Trechsel. 2014. Party Preferences in the Digital Age: The Impact of Voting Advice Applications. Party Politics 20 (2):227-36.

Arceneaux, Kevin, and Martin Johnson. 2013. Changing Minds or Changing Channels? Partisan News in an Age of Choice. Chicago, IL: University of Chicago Press.

Areni, Charles, and Richard Lutz. 1988. The Role of Argument Quality in the Elaboration Likelihood Model. Advances in Consumer Research 15:197-203.

Atkinson, Richard. 1972. Ingredients for a Theory of Instruction. American Psychologist 27 (10):921-31.

Bates, Marcia. 2002. Toward an Integrated Model of Information Seeking and Searching. New Review of Information Behaviour Research 3:1-15.

Bell, Bradford, and Steve Kozlowski. 2008. Active Learning: Effects of Core Training Design Elements on Self-Regulatory Processes, Learning, and Adaptability. Journal of Applied Psychology 93 (2):296-316.

Bruner, Jerome, Jacqueline Goodnow, and George Austin. 1956. A Study of Thinking. London: Chapman and Hall.

Case, Donald. 2007. Looking for Information: A Survey of Research on Information Seeking, Needs, and Behavior. New York: Academic Press.

De Vries, Catherine, Wouter van der Brug, Marcel van Egmond, and Cees van der Eijk. 2011. Individual and Contextual Variation in EU Issue Voting: The Role of Political Information. Electoral Studies $30: 16-28$.

Dinas, Elias, and Sergi Pardos-Prado. 2012. A Hidden Giant? Exploring the Centrifugal Dynamics of Attitudes Towards the European Unification. Acta Politica 47 (4):378-99.

Downs, Anthony. 1957. An Economic Theory of Democracy. New York: Harper.

Druckman, James, Jordan Fein, and Thomas Leeper. 2012. A Source of Bias in Public Opinion Stability. American Political Science Review 106 (2):430-54.

Gaines, Brian, and James Kuklinski. 2011. Experimental Estimation of Heterogeneous Treatment Effects Related to Self-Selection. American Journal of Political Science 55 (3):724-36.

Harman, Karin, Keith Humphrey, and Melvyn Goodale. 1999. Active Manual Control of Object Views Facilitates Visual Recognition. Current Biology 9:1315-18.

Hix, Simon, and Christopher Lord. 1997. Political Parties in the European Union. New York: Macmillan.

Hobolt, Sara, and Jill Wittrock. 2011. The Second-Order Election Model Revisited: An Experimental Test of Vote Choices in European Parliament Elections. Electoral Studies 30:29-40. 
Hooghe, Liesbet, and Gary Marks. 1999. The Making of a Polity: The Struggle Over European Integration. In Continuity and Change in Contemporary Capitalism, edited by Herbert Kitschelt, Peter Lange, Gary Marks and John Stephens, 70-97. Cambridge: Cambridge University Press.

Hurwitz, Jon, and Mark Peffley. 2005. Playing the Race Card in the Post-Willie Horton Era. The Impact of Racialized Code Words on Support for Punitive Crime Policy. Public Opinion Quarterly 69 (1):99-112.

Imbens, Guido. 2000. The Role of the Propensity Score in Estimating Dose-Response Functions. Biometrika 87 (3):706-10.

Iyengar, Shanto, Mark Peters, and Donald Kinder. 1982. Experimental Demonstrations of the 'NotSo-Minimal' Consequences of Television News Programs. American Political Science Review 76 (4):848-58.

Johnson, David. 1997. Cancer-Related Information Seeking. Cresskill, NJ: Hampton Press.

Kinder, Donald. 2003. Communication and Politics in the Age of Information. In Oxford Handbook of Political Psychology, edited by David O. Sears, Leonie Huddy and Robert Jervis, 357-93. Oxford: Oxford University Press.

Klapper, Joseph. 1960. The Effects of Mass Communications. Glencoe, IL: Free Press.

Lenz, Gabriel. 2009. Learning and Opinion Change, Not Priming: Reconsidering the Priming Hypothesis. American Journal of Political Science 53 (4):821-37.

Leotti, Lauren, Sheena Iyengar, and Kevin Oshsner. 2010. Born to Choose: The Origins and Value of the Need for Control. Trends Cognitive Science 14:457-63.

Markant, Douglas, Sarah DuBrow, Lila Davachi, and Todd Gureckis. 2014. Deconstructing the Effect of Self-Directed Study on Episodic Memory. Memory and Cognition 42 (8):1211-24.

Markant, Douglas, and Todd Gureckis. 2013. Is It Better to Select or to Receive? Learning Via Active and Passive Hypothesis Testing. Journal of Experimental Psychology 143 (1):94-122.

McGuire, William. 1985. Attitudes and Attitude Change. In Handbook of Social Psychology, 3rd Edition, Vol. 2, edited by Gardner Lindzey and Elliot Aronson, 233-346. New York: Random House.

Paas, Fred, Alexander Renkl, and John Sweller. 2004. Cognitive Load Theory: Instructional Implications of the Interaction Between Information Structures and Cognitive Architecture. Instructional Science $32: 1-8$.

Petty, Richard, and John Cacioppo. 1986. The Elaboration Likelihood Model of Persuasion. Advances in Experimental Social Psychology 19:123-205.

Rabinowitz, George, and Stuart Elaine Macdonald. 1989. A Directional Theory of Issue Voting. American Political Science Review 83 (1):93-121.

Reif, Karlheinz, and Herrmann Schmitt. 1980. Nine Second-Order National Elections: A Conceptual Framework for the Analysis of European Election Results. European Journal of Political Research 81:3-45.

Rosenbaum, Paul, and Donald Rubin. 1983. The Central Role of the Propensity Score in Observational Studies for Causal Effects. Biometrika 70 (1):41-55.

Sobel, David, and Tamar Kushnir. 2006. The Importance of Decision Making in Causal Learning from Interventions. Memory and Cognition 34 (2):411-19.

Steenbergen, Marco, André Bächtiger, Markus Spörndli, and Jürg Steiner. 2003. Measuring Political Deliberation: A Discourse Quality Index. Comparative European Politics 1 (1):21-48.

Stroud, Natalie. 2008. Media Use and Political Predispositions: Revisiting the Concept of Selective Exposure. Political Behavior 30 (3):341-66.

Sunstein, Cass. 2001. Republic.com. Princeton, NJ: Princeton University Press.

Tilley, James, and Christopher Wlezien. 2008. Does Political Information Matter? An Experimental Test Relating to Party Positions on Europe. Political Studies 56:192-214.

Van der Brug, Wouter, and Cees van der Eijk. 1999. The Cognitive Basis of Voting. In Political Representation and Legitimacy in the European Union, edited by Hermann Schmitt and Jacques Thomassen, 129-60. Oxford: Oxford University Press.

Van der Brug, Wouter, Mark Franklin, and Gábor Tóka. 2008. One Electorate or Many? Differences in Party Preference Formation Between New and Established European Democracies. Electoral Studies 27 (4):589-600. 
Van der Eijk, Cees, and Mark Franklin. 2004. Potential for Contestation on European Matters at National Elections in Europe. In European Integration and Political Conflict, edited by Gary Marks and Marco Steenbergen, 32-50. Cambridge: Cambridge University Press.

Van der Eijk, Cees, Wouter van der Brug, Martin Kroh, and Mark Franklin. 2006. Rethinking the Dependent Variable in Voting Behavior: On the Measurement and Analysis of Electoral Utilities. Electoral Studies 25 (3):424-47.

Vassil, Kristjan. 2011. Role of Self Selection in Estimating the Effects of Voting Advice Applications: Empirical Evidence on the Basis of Swiss Smartvote Data. 6th ECPR General Conference, Reykjavik, 25-27 August.

Voss, Joel, David Warren, Brian Gonsalves, Kara Federmeier, Daniel Tranel, and Neal Cohen. 2011. Spontaneous Revisitation During Visual Exploration as a Link Among Strategic Behavior, Learning, and the Hippocampus. Proceedings of the National Academy of Sciences 108:E402-9.

Weber, Till. 2007. Campaign Effects and Second-Order Cycles: A Top-Down Approach to European Parliament Elections. European Union Politics 8 (4):509-36.

- 2009. When the Cat is Away the Mice Will Play: Why Elections to the European Parliament are About Europe After All. Politique Européenne 28:53-71.

Zaller, John. 1992. The Nature and Origins of Mass Opinion. New York: Cambridge University Press. 